\title{
Do filial values corrupt? How can we know? Clarifying and assessing the recent Confucian debate $^{\dagger}$
}

\author{
Hagop Sarkissian \\ Department of Philosophy \\ The City University of New York \\ Graduate Center \& Baruch College
}

\begin{abstract}
In a number of papers, Liu Qingping has critiqued Confucianism's commitment to 'consanguineous affection' or filial values, claiming it to be excessive and indefensible. Many have taken issue with his textual readings and interpretive claims, but these responses do little to undermine the force of his central claim that filial values cause widespread corruption in Chinese society. This is not an interpretive claim but an empirical one. If true, it merits serious consideration. But is it true? How can we know? I survey the empirical evidence and argue that there is no stable or direct relationship between filial values and corruption. Instead, other cultural dimensions (such as high power distance and assertive materialism) are more robust predictors of corruption. As it happens, China ranks very high in these other cultural dimensions. I conclude that if the empirical research is correct, then Liu's claims lack direct empirical support.
\end{abstract}

\footnotetext{
${ }^{\dagger}$ Forthcoming in Dao: A Journal of Comparative Philosophy. Please cite the published version of the article.
} 


\title{
Do filial values corrupt? How can we know? Clarifying and assessing the recent Confucian debate
}

\author{
Hagop Sarkissian \\ Department of Philosophy \\ The City University of New York \\ Graduate Center \& Baruch College
}

\begin{abstract}
"If there is that which is especially dear [to us], then there is that which is not dear.
If there is that which we love, then there is that which we do not love. The Chinese, having the clan group, therefore hold dear those of the same surname, and [feel] estranged from those of different surnames."

- Kang Youwei, The Book of Great Unity ${ }^{1}$
\end{abstract}

Confucianism embraces a partialistic ethic, whereby family reverence, filial obligations, and kin considerations more broadly are central and weighty. No one seriously denies this as a descriptive claim. And yet, whether this is something good or bad has been debated at various times with the tradition itself. Indeed, adherents or admirers of the tradition have at times sought to part ways with it owing to its seeming overemphasis of filial values. This has continued through the modern period and up to the present day.

For example, KANG Youwei (1858-1927) is conventionally afforded membership in the Confucian intellectual tradition and, in many respects, led an exemplary Confucian life. He was initiated into Confucian philosophy from a young age, penned commentaries on seminal texts, passed the grueling civil service examinations, and counseled the penultimate Qing emperor. He even looked the part, routinely donning the scholar's skullcap, long gown, and embroidered jacket (Grieder 1983: 122). And yet, Kang's utopian Da Tong Shu 大同書 (Book of Great Unity) insists (against Confucian orthodoxy) that humans are inherently selfish and calculative, that refining and satisfying sensual pleasure is the highest good, and that self-cultivation is not an expedient path towards peace and happiness. Strikingly, Kang also censures the traditional family as divisive and incompatible with a harmonious society; partialism toward family must be abolished or else it will forever threaten to cause disunity, discord, and disorder. (He made similar comments about religions, nations, and racial identities.) As CHANG Hao notes, for Kang, "the family institution tends too easily to become the focus of loyalty of the individual person at the cost of the solidarity of the larger society" (Chang 1987: 61). (Kang himself realized the gravity of calling for the abolition of the family; when, at the behest of his pupils, he finally agreed to publish part of the Da Tong Shu, he left out much of his concrete policies-most notably the abolition of the family-believing his contemporaries not ready to accept them.)

\footnotetext{
${ }^{1}$ The translation is by Thompson (1958: 71))
} 
This is a constant refrain, which appears again and again throughout the $20^{\text {th }}$ century. For example, CHEN Duxiu (1879-1942) famously blamed Confucianism's emphases on filial piety (xiao 孝) and hierarchy as chief causes of China's stagnation. These aspects of Confucianism (along with traditional rites and roles) supported a servile, conservative, and retrogressive outlook. ${ }^{2}$ For China to progress, such values needed to be supplanted by a cosmopolitan, utilitarian, egalitarian, and progressive worldview. (Similar sentiments were expressed by a number of May Fourth intellectuals.)

In a number of papers spanning the first decade of the $21^{\text {st }}$ century, Lu Qingping has renewed this criticism (e.g. Liu 2003, 2007, 2009). His chief claim-that "consanguineous affection" (xue qin qing li 血親情理) corrupts Chinese society and must be jettisoned from Confucianism once and for all-garnered much scholarly attention. ${ }^{3}$ And yet, in spite of all the activity it spurred, some key issues remain unresolved. In what follows, I hope to bring some additional clarity to this debate. After outlining the main arguments on both sides, I will call for a separation of two issues that are often run together. The first issue is interpretive: has Confucianism emphasized filial values over more impartial values? The second issue is normative: should Confucianism emphasize filial values over more impartial values? As will be obvious, the answer to the former question has no direct bearing on the latter. Next, I will evaluate the avowed motivation of Liu's critique-namely, the role of "cosanguineous affection" in fostering systemic corruption in Chinese culture. As we will see, the kind of evidence Liu invokes here cannot establish his causal claim. In fact, empirical evidence (such as can be readily found) suggests that other cultural values might play a more substantial role in causing corruption. Finally, I suggest that it is irresponsible to call for wholesale changes in cultural values without seriously considering the costs in doing so. These costs, I argue, are hard to predict and likely significant.

\section{I - The Interpretive Questions ${ }^{4}$}

Why does the family play such a central role in Confucian ethics? A full answer cannot be provided here. ${ }^{5}$ However, the classical thinkers recognized that one's values and attitudes are shaped in foundational ways by one's familial environment; one's first experiences of the social and moral world occur under the supervision and guidance of one's family (such as one's parents or older siblings), where one learns about roles and hierarchies and how one fits into a

\footnotetext{
2 See, for example, Chen's "The Constitution and Confucianism", translated in Angle and Svensson (2015). Chen was likely influenced by Wu Yu 吴虞 (1872-1949) in this regard, though Wu emphasized the rule of law to a greater extent. My thanks to Kristin Stapleton for pointing this out.

${ }^{3}$ See, for example, the special issues of the journal Dao devoted to this topic (7.1 and 8.2). See also Guo (2004) for a collection of key papers.

${ }^{4}$ Readers familiar with this debate can skip until the last paragraph of this section.

${ }^{5}$ For a review of some of the recent literature on this question, see Sarkissian (2010b). For a collection of important essays covering the history and substance of filial piety in the Chinese tradition, see Chan and Tan (2004). Radice's (2018) recent review is also a good source.
} 
web of interconnected relationships, each with its attendant duties and spheres of influence. Families thus prepare one to enter a world filled with demands and reciprocal ties with others; elders have obligations to nurture the young, who in turn must be devoted and obedient. As parents age, children must care for them out of love and a sense of gratitude for the care they themselves received, while being prepared to gently remonstrate them for bad behavior. In short, it is in the family context that one learns how to feel and react in a range of situations central to social life, instilling in one virtuous dispositions such as dutifulness or conscientiousness (zhong 忠), respect (jing 敬), and benevolence (hui 惠). The family thus cultivates moral norms into an individual's emotional repertoire, affecting how he or she will reflect or respond to situations later in life (Sarkissian 2010a). The family must discharge this role with concern and devotion, as failure at this stage is hard to correct later in life.

All participants in the debate agree that Confucianism values the family. Yet Liu argues that filial values are emphasized too much. His criticisms hinge on a couple of interpretive questions, which I consider next, and over which much ink has been spilled.

The first interpretive question can be stated as follows: does the Confucian tradition trumpet filial virtues and values at the expense of other, more expansive virtues and values -in particular, the virtue of humankindness (ren 仁)? This question has been debated throughout the history of Confucianism (e.g. Chan 2004), and Liu maintains that the answer to this question is 'yes'. In order to make his case, Liu draws on general statements in the Confucian corpus (e.g. the Analects and the Mengzi) speaking to the supreme importance of filial piety. Some passages do seem to support the idea that xiao has primacy over ren; Youzi, for example, comments that filial devotion and brotherly respect are the roots of ren (Analects 1.2), ${ }^{6}$ and Kongzi argues that filial devotion must be realized before one can care for others (1.6). These passages suggest some primacy for filial devotion. Similarly, the Mengzi claims that there is no greater virtue or service than honoring one's parents (e.g. 4A19, 5A4), the Doctrine of the Mean claims that being affectionate toward one's relatives is ren's greatest application (Chan 1963: 104), and the Classic of Filial Devotion sees all other virtues as stemming from filial devotion (see Chan 2004). This is enough to attest to the importance of filial morality generally in Confucianism, and might explain why Liu argues that it puts filial devotion in "paramount position" as the "fundamental spirit running through the whole framework of Confucianism" (Liu 2003: 240).

And yet, filial piety is not the only virtue the Confucians emphasized, nor is it clearly the most important. After all, benevolence or humankindness (ren 仁)-a strong sense of compassion towards and identification with others-is regularly ranked as the highest virtue in the Confucian tradition. While the precise meaning of ren varies from thinker to thinker, in its broad sense it represents an unparalleled moral achievement that few attain yet to which all should aspire. In this sense, May Sim describes ren as "the highest Confucian virtue" (Sim 2007:

\footnotetext{
${ }^{6}$ In Sarkissian (2010b), I had mistakenly attributed this statement to Kongzi himself (as dozens of others have done and continue to do). My thanks to Bill Haines for pointing this out. On the general (and regrettable) tendency of scholars to attribute Youzi's statements to Kongzi, see Haines (2008).
} 
7), Kwong-loi Shun as "an all-encompassing ethical ideal which includes all the desirable qualities" (Shun 1993: 457), and Benjamin Schwartz as "an attainment of a human excellence which-where it exists-is a whole embracing all the separate virtues" and "the highest ideal of personal excellence" (Schwartz 1985: 75, 82).

The second interpretative question, as I see it, is not about relative primacy of xiao over ren, or of partial values over comparatively impartial values, but rather about whether Confucianism endorses a culture of corruption and the loosening of moral standards in the interest of filiality. Here, a key part of Liu's argument hinges on a number of particular cases where Confucian thinkers laud or approve of behavior that is both filial and (according to Liu) highly corrupt, favoring or giving weighty consideration to one's family's interests over the public's interest when the two come into conflict. Consider Analects 13.18, where the Duke of She praises a man nicknamed "Upright Gong" for turning in his father to the authorities for the crime of stealing a sheep. Kongzi claims that being "upright' is just the opposite: "fathers cover up for sons, and sons cover up for their fathers. 'Uprightness' is to be found in this" (Slingerland 2003: 147). Consider, too, Mengzi 7A35, where we find Mengzi confronted by a hypothetical moral dilemma: suppose that the father of the sage king Shun were to commit murder: would Shun use his royal power to protect his father from criminal prosecution? Mengzi claims that in such a situation Shun could not stand in the way of justice, or simply stand by while his father was prosecuted. What's his answer, then? Shun, he claims, would simply abdicate the throne and flee to the coast secretly with his father, to live out his years in filial happiness. Here, Shun is praised for abdicating the throne, abandoning his people, and evading just prosecution. We find similar sentiments expressed in 5A3, where Mengzi approves of Shun granting his morally depraved, vicious brother a fief because doing so discharged his filial obligation to ennoble his own family. In these cases, Liu argues, we see a plain conflict between filial devotion and public justice, with the former prevailing in each instance. Liu argues that Confucianism "will naturally tolerate and even endorse such actions as bending the law for the benefit of relatives and appointing people by nepotism" even though they might "injure social justice and the public interest" (Liu 2007: 7). To move in a progressive direction, Confucianism must replace its emphasis on kin relations with a more universal ethic, leading the way to a new brand of PostConfucianism, which would value universal love well ahead of filial love.

In response, some have charged that Liu does not pay sufficient attention to the details of the cases in question. When understood in their contexts, the behaviors do not reflect corruption at all. For example, when Kongzi claims that fathers would cover for their sons and sons for their fathers, he says so in the context of a conversation about stealing a sheep. During that time, the punishment for stealing a sheep would likely be mutilation, such as the amputation of the thief's hand or foot, or having the word "criminal" forcibly tattooed on the thief's forehead. One can thus understand a son's reluctance to immediately turn his father over to the authorities when the punishment would be so severe (see, e.g. Rosemont and Ames 2008; Van Norden 2008). Others emphasize the need to fulfil the filial duty to remonstrate with one's parents and set them on the right path, which requires preserving the relationship with 
them (hence not turning the father in) while also being determined to persist in the remonstration, gently but firmly (e.g. Bai 2008; Huang 2012; cf. Li 2012). Still others have argued that Confucianism seeks to optimally balance and maximize a number of competing values-some of them partial or favoring family, others more impartial or devoted to public concerns. For example, the sage king Shun does not shield his murderous father from prosecution and also places the administration of his brother's fiefdom in capable hands. In these cases more impartial concerns do matter and do hold sway, thus showing a commitment to broader concerns (e.g. Angle 2008). Indeed, Liu himself recognizes that preferential treatment of kin by public officials runs against Confucian doctrine pertaining to humane governance and beneficent rule (Liu 2007: 7). Finally, some have claimed that norms privileging family relations and allowing for preferential treatment of kin are ubiquitous and found in cultures around the world and throughout time; if Confucianism emphasizes them then it is no different than most other traditional moralities and legal codes (e.g. Guo 2007: 33).

I won't attempt to resolve either of the interpretive questions here. First, nearly all of the existing responses have focused on these interpretive questions, and there have been several exchanges revealing the richness of the tradition and how it has strained, admirably, to meet conflicting demands and competing values. There is little to add in this regard. Second, even if filial values are not meant to trump more impartial ones in theory, it might be the case that they will often do so in practice; remonstrating with one's parents, for example, might be psychologically difficult and wholly ineffectual, notwithstanding the injunction to do so. Third, and most importantly, Liu can reasonably claim that even if the interpretive question is decided against him, this does not mean that filial values play no role in causing corruption. After all, the core of Liu's argument, as I see it, is that filial values corrupt Chinese society. If this claim is true, then whatever one thinks of the interpretive questions above, fostering corruption would constitute a serious, weighty reason to abolish Confucian consanguineous affection all on its own.

\section{II - The Normative Question}

The case that Liu makes is, at its heart, normative: Confucianism (or New Confucianism, or Post-Confucianism) should jettison filial piety as a cardinal virtue, and move filial values to the periphery in general. And, as noted, this question is orthogonal to the one above; it cannot be answered by settling the issue of whether Confucianism has emphasized filial piety over impartial concerns. The tradition has changed over time and continues to evolve, and this might be a good change to make. All that is required for Liu's argument to be pressing is for filial values to (a) be weighty and (b) cause corruption. No one denies the former. What of the latter, then? How does Liu establish his case?

Apart from the examples of Confucian paragons engaging in seemingly corrupt behavior, Liu appeals to broad and rather plausible-sounding generalizations. For example, Liu claims that 
filial piety can cause a "predisposition to secure advantages through blood ties, to appoint people on the basis of favoritism, to bend the law for the benefit of relatives, and to engage in various prevailing corrupt practices" (Liu 2003, 246). By 'corruption', Liu means the practice of securing benefits for one's family at the expense of the public interest and in direct violation of the law. Liu admits that it would be unreasonable to blame consanguineous affection alone for all corrupt practices in China. He mentions, for example, other tendencies.

Moreover, there are some other kinds of corrupt practices or so-called, "unhealthy tendencies" (bu zheng zhi feng 不正之風) prevalent in contemporary Chinese society, such as la guan $x i$ 拉關係 (establishing special relations with someone special), zou hou men 走後門 (getting in by the back door), qun dai wang 裙帶網 (the network connected via one's maternal relatives), jie bang pai 結幫派 (forming cliques), taking or giving a bribe from or to somebody who stands in a special relation to oneself, and so on. (Liu 2007: 7)

However, Liu almost immediately backtracks on this qualification. He suggests that all of these corrupt practices stem from a prior commitment to filial values, and their role in shaping a culture that accepts privileging particular bonds over universal principles. "Unfortunately," he writes, "it is the Confucian spirit of 'consanguineous affection' that plays the key role of initiator in establishing such an idea in the deep psychocultural construct of the Chinese tradition" (ibid). So perhaps it is to blame after all.

Now, this claim - that filial values corrupt-is an empirical claim; it is (ostensibly) about the observable world. However, the bulk of the evidence for it is decidedly not empirical; to support his case, Liu cites, as evidence, passages from philosophical texts, anecdotes, and prevailing sentiments and stereotypes. Of course, the perception of China as a corrupt nation is undeniable (as measured, for example, by Transparency International), as is Confucianism's emphasis on filial values. But is it obvious that these two things are causally related? What, exactly, causes corruption in Chinese society? The original exchanges between Liu and his critics, as well as a second, extended round of this debate (summarized helpfully in Wang 2014), fail to address this question. In the next section, I will attempt to fill this lacuna. ${ }^{7}$

\footnotetext{
${ }^{7}$ Some proponents of the view that filial values do not lead to corrupt behavior might argue as follows: any form of corrupt behavior is inconsistent with filial values, so any seeming instance of corruption caused by persons acting on filial values is either a) really not corruption, properly understood or b) really not driven by filial values, properly understood. On such a view, there would be no need to look at empirical studies (as will be done below), as it can be known from the armchair that filial values just do not lead to corrupt behavior. Yet this would seem to sever the relationship between Confucianism as a theory and Confucianism as a continuing cultural tradition, and all parties seem to consider Confucianism to be both of these. Indeed, if Confucianism values and ideals were inert and without application, it seems hard to make sense of why the participants in this debate think societal corruption is relevant at all. Moreover, and insofar as Confucianism is both theory and practice, one might be concerned with how individuals interpret and enact its commitments, and how the tradition itself has handled cases that seem
} 


\section{III - Cultural Values and Corruption-The Empirical Case}

Given the enormous importance of corruption (or the abuse of entrusted power for private gain), measuring and understanding it has been the focus of sustained research in the social sciences for some time. With the exception of some small, micro-level case studies, most measures of corruption rely upon surveys of the general public, as well as business people and privately contracted researchers, who report their perceptions of corruption, as actual levels of corruption are oftentimes unknown and difficult to uncover (Lambsdorff 1999).

There are numerous proposed causes of corruption, spanning social, political, economic, legal, governmental, and cultural factors (see, e.g. Judge, McNatt, and Xu 2011; Lambsdorff 1999; Park 2003). So measuring corruption is a complicated task. Even if one is confident in one's assessment of the existence of corruption, there is also a meta-level issue of coming to a precise relationship between corruption and any particular correlational factor: does the factor itself cause the corruption, or does corruption give rise to that factor? For example, if corruption is correlated with poverty at the national level, are we to conclude that corruption causes poverty, or does poverty force individuals to engage in corrupt practices to ensure their survival? To choose a more germane example: do filial bonds corrupt society, or does a corrupt society force people to rely upon informal networks of mutual support, such as filial or kin ties? (On such a reading of Analects 13.18, for example, one might claim that punishing practices were so barbaric or corrupt that they fostered a tendency for kin to conceal for one another.)

At any rate, we can look to the literature exploring the relationship between cultural values on the one hand, and corruption on the other, so as to better evaluate Liu's claims. Consanguineous affection is described by Liu as a dominant cultural value and orientation, rooted in Confucian philosophy, that causes corruption in Chinese society. And existing research on cultural values and levels of corruption can help us evaluate this specific claim in a way that goes beyond invoking sentiments and stereotypes, and appealing to anecdotes and intuitions. Much of the work done on the influence of culture on corruption at the national level has made use of the research of Gert Hofstede on dimensions of national culture, originally constructed by analyzing a large data set of value surveys completed by employees of IBM in more than 70 countries between 1967 and 1973 (Hofstede 1980). Subsequent studies have been run on other subject pools, such as airline pilots, students, and high-income consumers. These have tended to confirm the data culled from the IBM surveys, and this research program continues today. In its current form, the database scores 76 nations along six cultural dimensions (Hofstede, Hofstede, and Minkov 2010). Of these six, two seem directly related to Liu's consanguineous affection: power distance and collectivism.

Power distance is a measure of various power imbalances, such as how afraid subordinates are to express disagreement with their superiors, or whether superiors follow an

to involve a conflict between filial values and comparatively impartial ones. These questions require some engagement with Confucianism as a lived tradition, hence empirical research can be helpful. 
autocratic or paternalistic decision-making style. More generally, this variable refers to whether the less powerful members of institutions and organizations within a given society simply accept that power is distributed unequally-for example, whether the powerful are entitled to privileges denied to others. It can be hypothesized that in cultures high in power distance, illegal uses of power for personal gain often go unchallenged by inferiors and will therefore be more prevalent. Filial piety has features in common with power distance, including the acceptance of hierarchical relationships each with its attendant (and asymmetrical) duties and expectations. While remonstration with parents is encouraged in Confucianism (Huang 2012 chapter 5), it remains the case that obedience and deference to family, and to elders more broadly (e.g. Analects 1.2) is a feature of filial piety, and so even while power distance, as a cultural dimension, has nothing to do with kin relations per se, it can serve as an analogue of this very specific, and very central, feature of filial piety in the Confucian tradition having to do with deference to hierarchy.

A country is characterized as being high in collectivism if its people are integrated into strong, cohesive ingroups, consisting of family, close friends, and peers, to which they must be loyal. Groups protect individual members, who in turn are loyal to the groups. It can be hypothesized that such partialism and loyalty can encourage corruption, as group members may not be willing to speak out against a fellow member and will instead conform with any existing corrupt practices. More generally, there will be tolerance of bad behavior by superiors within the ingroup (e.g. Bond et al. 1985), and group loyalty will undermine other values when they come into conflict, such as fairness or efficiency. Consanguineous affection has obvious similarities with collectivism as well, especially as outlined by Liu who, as seen above, links partialism and group loyalties to it directly. Thus, even while collectivism, as a cultural dimension, extends beyond family or kin to different types of in-groups, it can serve as an analogue of the aspects of consanguineous affection that emphasize deference and loyalty to one's family, which is considered to be the most important in-group of all.

Finally, while not obviously related to consanguineous affection at first glance, assertive materialism $^{8}$ is another cultural dimension that will also be discussed below. This variable measures the extent to which a national culture values assertiveness, material success, and personal wealth over broader social concerns and quality of life. Societies high in this variable tend to believe that exaggerated manhood (or machismo) is a good thing, that one's work should take priority over other considerations (such as one's family), that there should be strong divisions of activity by gender (e.g. females should be relegated to domestic duties), and that material wealth is a marker of success.

\footnotetext{
8 'Masculinity' is Hofstede's own chosen label for this dimension, but it has proved so distracting in my experience that I substitute 'assertive materialism' for it throughout this paper. The distracting nature of the label is something Hofstede et al note, and they encourage others to come up with their own labels (Hofstede, Hofstede, and Minkov 2010: 144)
} 
China is high in power distance (ranking 12th out of the 76 countries in Hofstede's database), collectivism (ties for 14th) and assertive materialism (tied for 11th) (Hofstede et al. 2010). While it has roughly equal levels of collectivism when compared to other countries with a Confucian heritage such as Taiwan and South Korea, it is much higher than them in the other two dimensions. See Figure 1. How are these cultural dimensions related to corruption?

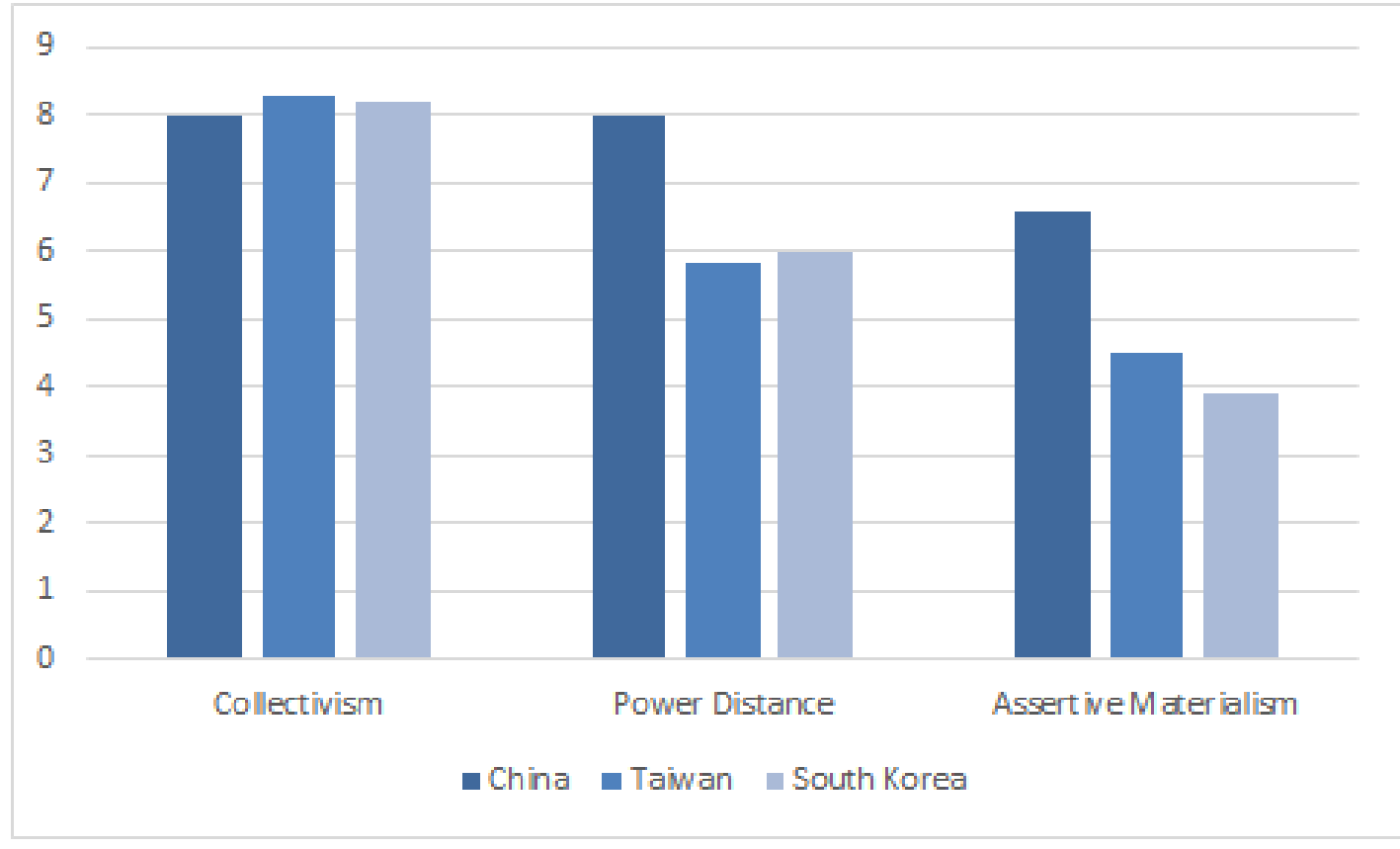

Figure 1. Comparison of cultural dimensions among three countries with Confucian heritage: China, Taiwan, and South Korea (Hofstede et al. 2010)

Empirical research on the relationship between these variables and a corruption shows a fairly cohesive picture. Park (2003) analyzed data from 37 countries, finding several macrolevel factors to be predictive of corruption. Socio-political instability and lack of economic freedom explained the most variance when it came to levels of perceived corruption, with legitimacy of legal institutions also having smaller (though significant) predictive power. Alongside these variables, though, Park looked at the cultural factors noted above. Levels of aggressive materialism and power distance were also positively correlated with perceived levels of corruption. Levels of collectivism, by contrast, had no significant relationship with corruption. In a study of 47 countries, Richardson (2006) found that, controlling for economic development, democracy, and government size, power distance and uncertainty avoidance (another of Hofstede's cultural dimensions, measuring the degree to which individuals find ambiguous or unknown situations to be threatening) were found to predict corruption. Getz and Volkema (2001), in a study of 50 countries, found the same pattern for the cultural variables. In each of these cases, levels of collectivism had no predictive power. In a separate study of 42 countries, Davis and Ruhe (2003) found that, when accounting for the impact of various economic factors (such as government spending and per capita income), each of the three cultural dimensions noted above (power distance, collectivism, and assertive materialism) were in fact positively 
correlated with corruption, with assertive materialism being the most robust predictor (i.e. least likely to be related to corruption by chance alone). ${ }^{9}$

In the most relevant study for present purposes, Husted (1999) examined data from 44 countries, looking at both economic and cultural variables. Among the latter, high power distance, assertive materialism, and uncertainty avoidance were found to correlate with corruption. This coheres with the studies above. However, in addition to looking at overall correlations across the sample, Husted analyzed the data in finer detail, looking at the predictors for high and low collectivist countries separately, and high and low power distance countries separately. He found a very parsimonious model for countries that are high in power distance or high in collectivism: in such countries, assertive materialism "is the single cultural variable that contributes to corruption" (Husted and de Estudios 1999: 354). See Figure 2.

\footnotetext{
${ }^{9}$ The findings for high power distance and collectivism were significant at the .05 level, whereas the finding for assertive materialism was significant at the .001 level.
} 


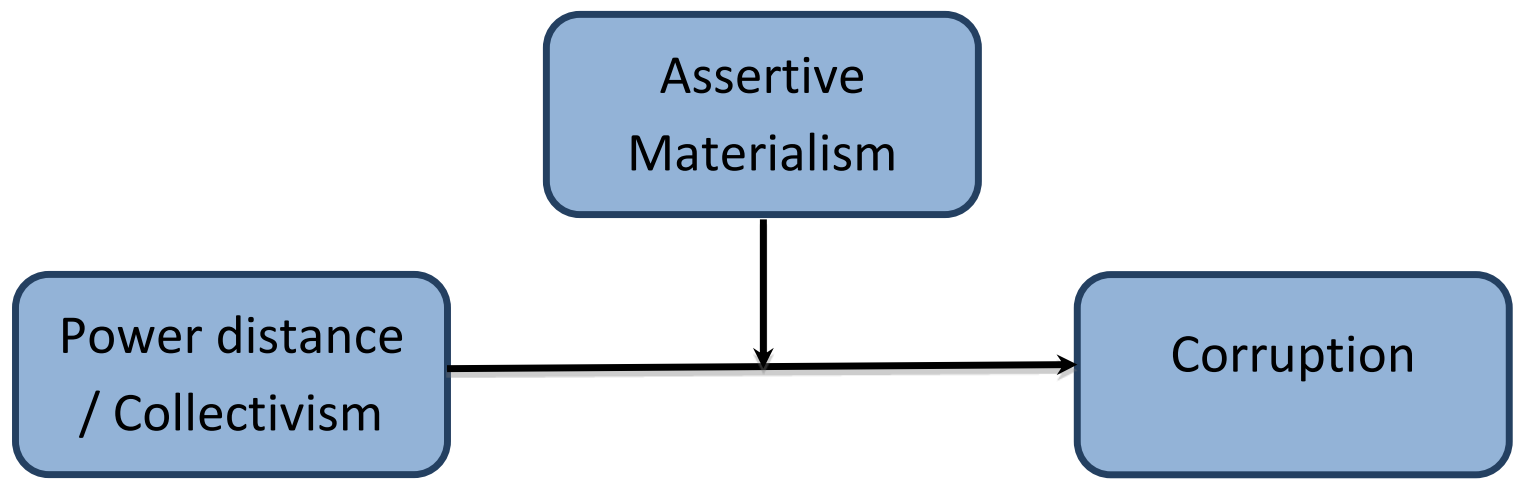

Figure 2. Assertive materialism as a moderating variable affecting the relationship between power distance and collectivism on corruption.

This empirical result makes intuitive sense. Whether a society has collectivist values or whether it is organized in a more hierarchical fashion is one thing, and whether these are exploited for personal gain is another. Take a prototypical case of corruption, where an official uses his position to seek private gain for himself or his family. Is it consanguineous affection that is driving this behavior? Is it merely that the person is a superior and thus able to silence any subordinates? Or is it instead a desire for profit or personal gain that ultimately drives the behavior? It seems reasonable to explain a person's engaging in illicit practices for private gain by appealing to the private gain itself. Collectivism and high power distance may constitute part of the enabling conditions that would help facilitate corrupt practices, but the impetus to engage in corruption seems to require some further desire, motive, or drive. Indeed, a nation may successfully combat corruption while maintaining an emphasis on collectivism (Huang et al. 2015).

Assertive materialism, then, seems to have greater explanatory power. Societies high in this orientation exalt wealth acquisition and material gain, which may motivate individuals to exploit family relations and power imbalances for corrupt purposes. In the absence of such a value orientation, or with very different criteria for self-esteem or success, the relationship with corruption makes less sense. (Assertive materialism is also related to other negative social factors, such as gender inequality, which might exacerbate power distance.) Perhaps marshalling consanguineous affection toward cooperative well-being, ${ }^{10}$ a feature of societies that are low on assertive materialism, might be more effective at fighting corruption (see Table $1)$.

\begin{tabular}{|l|l|l|}
\hline Assertive Materialism & $\leftarrow \rightarrow$ & Cooperative Well-Being \\
\hline
\end{tabular}

\footnotetext{
${ }^{10}$ Hofstede's term for this end of the dimension is 'femininity', which is equally distracting. See footnote 7.
} 


\begin{tabular}{|c|c|c|}
\hline Wealth most important & $\leftarrow \rightarrow$ & Quality of life most important \\
\hline Purpose of life is to work & $\leftarrow \rightarrow$ & Work is a means to a good life \\
\hline Preference for higher pay & $\leftarrow \rightarrow$ & Preference for fewer working hours \\
\hline Economic growth prioritized & $\leftarrow \rightarrow$ & Environmental care prioritized \\
\hline Large gender wage gap & $\leftarrow \rightarrow$ & Small gender wage gap \\
\hline Low gender egalitarianism & $\leftarrow \rightarrow$ & High gender egalitarianism \\
\hline
\end{tabular}

Table 1 - Assertive materialism and cooperative well-being as related to socio-economic factors (Hofstede et al. 2010)

Finally, since Liu is concerned with how filial values affect the behavior and practices of populations of individuals, it would be worthwhile to see how individuals themselves understand the concept. For example, the virtue of filial piety has at least two different senses in Confucian populations: reciprocal filial piety, and authoritarian filial piety (Yeh 2003). Reciprocal filial piety "encompasses emotionally and spiritually attending to one's parents out of gratitude for their efforts in having [raised] one, and physical and financial care for one's parents as they age and when they die for the same reason" (Yeh and Bedford 2003: 216). This conception of filial piety fosters beneficial effects, including enhanced interpersonal relationships. Authoritarian filial piety, by contrast, entails "suppressing one's own wishes and complying with one's parents' wishes because of their seniority in physical, financial or social terms, as well as continuing the family lineage and maintaining one's parents' reputation because of the force of role requirements" (ibid). This conception fosters hierarchy and submission. Of course, these two kinds of filial piety represent general models and not mutual exclusive types; they co-exist both within populations and within individuals. However, by calling for a blanket rejection of partialist values from Chinese culture, Liu risks rejecting what is good along with what is bad.

Moreover, and despite significant demographic shifts in China, filial values remain both central and implicated in the well-being of many, including vulnerable populations such as the young and the elderly. Studies show that filial piety has remained stable as a cultural value, especially among the educated (e.g. Cheung, Kwan, and Ng 2006; Hu and Scott 2016; Xie 2013), even while it has come under tremendous amounts of pressure owing to challenges arising from the single child policy and attendant economic constraints (Chou 2011; Zhan and Montgomery 2003; Zimmer and Kwong 2003). Perceived filial piety is also important to the well-being of the elderly (e.g. Dong et al. 2012; Mao and Chi 2011; Wang et al. 2009). For example, seniors in Hong Kong feel the failing of filial piety most acutely when they are in times of need (such as when they are suffering illness or distress), and lack of filial respect predicted lower levels of psychological well-being (Cheng and Chan 2006). To be fair, Liu admits that filial piety has some positive effects that ought to be weighed against its negative effects (Liu 2003: 246-47). 
However, whereas Liu finds the negative effects of filial piety to outweigh the positives, a review of some of the evidence suggests a much more complicated story.

\section{IV - Conclusion}

The central question is: how will Confucianism respond to the critical challenges it faces in these modern times? More precisely, how can it maintain its traditional identity as "Confucianism" if it must let go of its insistence on the primacy of filiality in order to allow the realization of both individuality and sociality as equally important dimensions of the ideal person-and keep these three dimensions in harmony? How this question is answered may ultimately decide the fate of Confucianism. (Liu 2003: 247)

China is perceived to be considerably corrupt. How should Chinese intellectuals go about fighting this corruption? The above considerations suggest that, contra Liu, rejecting consanguineous affection may not help ameliorate corruption. Research suggests, generally, that culture plays only a partial role in causing corruption, and among cultural factors it may be assertive materialism that fosters a culture of corruption in highly collectivist and high power distance countries.

Why the focus on filial values, then? As mentioned at the outset, this has been a constant refrain throughout Chinese history. And it is indeed undeniable that if one wants to find cases where filial values have fostered particular acts of corruption, one need not search very far. The historical record is littered with particular cases, and these continue well into the present day. More generally, it seems there are indeed aspects of filial values that may contribute to a culture of corruption, and these might therefore be selectively de-emphasized. Power distance within a family context might indeed foster a tendency for family to cover for one another. What's more, Confucian filial values have historically been implicated in deeply sexist practices (e.g. Angle 2012 chapter 7; Herr 2003; Rosenlee 2006 chapter 6), which are components of aggressive materialism and predict higher levels of corruption. However, partialism itself-the main target of Liu's criticisms-need not to be a significant contributing factor.

More broadly, instead of trying to fight corruption by changing cultural values, one can try designing policy instruments that would make use of existing values in order to fight corruption and promote greater integrity. An effective policy to fight corruption in countries with high assertive materialism, for example, might be to promote anti-corruption programs like information sharing and merit-based practices, which can also be touted as contributing to material success - an existing cultural orientation (Husted and de Estudios 1999). After all, changing a culture is a difficult thing to do and will not occur overnight. Policy changes, by contrast, might be implemented comparatively quickly and can work with existing values without needing to radically change them. 
Liu desires increased sociality and individualism in Chinese culture. This desire may stand on its own. However, it would require a different justification. As it stands, censuring consanguineous affection out of a concern for corruption might be unjustified.

\section{ACKNOWLEDGEMENTS}

This paper benefited from feedback at the "Beyond New Confucianism" conference (SUNY Buffalo), the Singapore-Hong Kong-Macau Symposium on Chinese Philosophy (Hong Kong Baptist University), and the departments of Philosophy and Religious Studies at Sogang University. Special thanks to Steve Angle, So-Yi Chung, Myeong-seok Kim, and Janghee Lee for helpful discussion, and to Tze-ki Hon, Aram Kang, Kristin Stapleton, and two anonymous referees for their critical comments on previous drafts.

\section{REFERENCES}

Angle, Stephen C. 2008. “No Supreme Principle: Confucianism's Harmonization of Multiple Values." Dao 7.1: 35-40.

Angle, Stephen C. 2012. Contemporary Confucian Political Philosophy. Cambridge: Polity Press.

Angle, Stephen C. and Svensson, Marina. 2015. The Chinese Human Rights Reader: Documents and Commentary, 1900-2000. New York: Routledge.

Bai, Tongdong. 2008. "Back to Confucius: A Comment on the Debate on the Confucian Idea of Consanguineous Affection." Dao 7.1: 27-33.

Bond, Michael H., Wan, Kwok-Choi, Leung, Kwok, and Giacalone, Robert A. 1985. "How Are Responses to Verbal Insult Related to Cultural Collectivism and Power Distance?" Journal of Cross-Cultural Psychology 16.1: 111-27.

Chan, Alan K. L. 2004. “Does xiao Come before ren?" Pp. 154-75 in Filial Piety in Chinese Thought and History, edited by Alan K. L. Chan and Sor-Hoon Tan. London: RoutledgeCurzon.

Chan, Alan K. L. and Tan, Sor-Hoon, eds. 2004. Filial Piety in Chinese Thought and History. London: RoutledgeCurzon.

Chang, Hao. 1987. Chinese Intellectuals in Crisis, Search for Order and Meaning, 1890-1911. Berkeley: University of California Press.

Chan, Wing-Tsit. 1963. A Source-Book in Chinese Philosophy. Princeton: Princeton University Press. 
Cheng, Sheung-Tak and Chan, Alfred C. M. 2006. "Filial Piety and Psychological Well-Being in Well Older Chinese." The Journals of Gerontology. Series B, Psychological Sciences and Social Sciences 61.5: P262-69.

Cheung, Chau-Kiu, Kwan, Alex Yui-Huen, and Ng, Sik Hung. 2006. "Impacts of Filial Piety on Preference for Kinship versus Public Care." Journal of Community Psychology 34.5: 617-34.

Chou, Rita Jing-Ann. 2011. "Filial Piety by Contract? The Emergence, Implementation, and Implications of the 'Family Support Agreement' in China." The Gerontologist 51.1: 3-16.

Davis, James H. and Ruhe, John A. 2003. "Perceptions of Country Corruption: Antecedents and Outcomes." Journal of Business Ethics 43.4: 275-88.

Dong, Xinqi, Chang, E. Shien, Wong, Esther, and Simon, Melissa. 2012. "A Qualitative Study of Filial Piety among Community Dwelling, Chinese, Older Adults: Changing Meaning and Impact on Health and Well-Being." Journal of Intergenerational Relationships 10.2: 131-46.

Getz, Kathleen A. and Volkema, Roger J. 2001. "Culture, Perceived Corruption, and Economics: A Model of Predictors and Outcomes." Business \& Society 40.1: 7-30.

Grieder, Jerome B. 1983. Intellectuals and the State in Modern China. Simon and Schuster.

Guo, Qiyong. 2007. "Is Confucian Ethics a 'consanguinism'?" Dao: A Journal of Comparative Philosophy 6.1: 21-37.

Guo, Qiyong 郭齐勇. 2004. Collected Papers on a Debate about Confucian Ethics: Centered on Mutual Concealment Among Kin 儒家伦理争鸣集: 以 [亲亲互隐] 为中心. Wuhan 武漢: Hubei Jiaoyu Chubanshe 湖北教育出版社.

Haines, William A. 2008. "The Purloined Philosopher: Youzi on Learning by Virtue." Philosophy East \& West 58.4: 470-91.

Herr, Ranjoo Seodu. 2003. "Is Confucianism Compatible with Care Ethics? A Critique." Philosophy East \& West 53.4: 471-89.

Hofstede, Geert. 1980. Culture's Consequences: International Differences in Work-Related Values. New York: SAGE Publications.

Hofstede, Geert, Hofstede, Gert Jan, and Minkov, Michael. 2010. Cultures and Organizations: Software of the Mind, Third Edition. New York: McGraw Hill.

Huang, Yong. 2012. Confucius: A Guide for the Perplexed. London: Bloomsbury Publishing.

Huang, Zhen-Wei, Liu, Li, Zheng, Wen-Wen, Tan, Xu-Yun, and Zhao, Xian. 2015. “Walking the Straight and Narrow: The Moderating Effect of Evaluation Apprehension on the 
Relationship between Collectivism and Corruption." PloS One 10.3: e0123859.

Husted, Bryan W. and de Estudios, Instituto Tecnologico y. 1999. "Wealth, Culture, and Corruption." Journal of International Business Studies 339-59.

$\mathrm{Hu}$, Yang and Scott, Jacqueline. 2016. "Family and Gender Values in China: Generational, Geographic, and Gender Differences." Journal of Family Issues 37.9: 1267-93.

Judge, William Q., McNatt, D. Brian, and Xu, Weichu. 2011. "The Antecedents and Effects of National Corruption: A Meta-Analysis." Journal of World Business 46.1: 93-103.

Lambsdorff, Johann Graf. 1999. "Corruption in Empirical Research: A Review." Transparency International 6. Retrieved (https://www.researchgate.net/profile/Johann_Lambsdorff/publication/220011287_Corru ption_in_Empirical_Research_A_Review/links/00b4952722c1744928000000.pdf).

Liu, Qingping. 2003. "Filiality versus Sociality and Individuality: On Confucianism as 'Consanguinitism.'” Philosophy East \& West 234-50.

Liu, Qingping. 2007. “Confucianism and Corruption: An Analysis of Shun's Two Actions Described by Mencius." Dao: A Journal of Comparative Philosophy 6.1: 1-19.

Liu, Qingping. 2009. "To Become a Filial Son, a Loyal Subject, or a Humane Person?-On the Confucian Ideas about Humanity." Asian Philosophy 19.2: 173-88.

Li, Yong. 2012. "The Confucian Puzzle." Asian Philosophy 22.1: 37-50.

Mao, Weiyu and Chi, Iris. 2011. "Filial Piety of Children as Perceived by Aging Parents in China." International Journal of Social Welfare. Retrieved (http://onlinelibrary.wiley.com.ezproxy.library.ubc.ca/doi/10.1111/j.14682397.2011.00826.x/full).

Park, Hoon. 2003. "Determinants of Corruption: A Cross-National Analysis." Multinational Business Review 11.2: 29-48.

Radice, T. 2017. "Confucius and Filial Piety." In A Concise Companion to Confucius, edited by Paul Goldin. Hoboken: Wiley Blackwell, pp. 185-207.

Richardson, Grant. 2006. "The Influence of Culture on Fiscal Corruption: Evidence across Countries Tax Law and Political Institutions." Law in Context: A Socio-Legal Journal 24.: 124-42.

Rosemont, Henry, Jr and Ames, Roger T. 2008. “Family Reverence (xiao 孝) as the Source of Consummatory Conduct (ren 仁)." Dao 7.1: 9-19. 
Rosenlee, Li-Hsiang Lisa. 2006. Confucianism and Women: A Philosophical Interpretation. Albany: Suny Press.

Sarkissian, Hagop. 2010a. "Confucius and the Effortless Life of Virtue." History of Philosophy Quarterly 27.1: 1.

Sarkissian, Hagop. 2010b. "Recent Approaches to Confucian Filial Morality." Philosophy Compass 5.9: 725-34.

Schwartz, Benjamin I. 1985. The World of Thought in Ancient China. Cambridge: Belknap Press of Harvard University Press.

Shun, Kwong-Loi. 1993. "Jen and Li in the Analects." Philosophy East \& West 43.3: 457-79.

Sim, May. 2007. Remastering Morals with Aristotle and Confucius. New York: Cambridge University Press.

Slingerland, E. G. 2003. Confucius Analects: With Selections from Traditional Commentaries. Hackett Publishing.

Thompson, Laurence Cassius. 1958. Ta T'ung Shu: The One-World Philosophy of K'ang Yuwei. Translated from the Chinese with Introduction and Notes by Laurence $G$. Thompson. London: George Allen \& Unwin.

Van Norden, Bryan W. 2008. “On 'humane Love' and 'kinship Love.'” Dao 7.2: 125-29.

Wang, Dahua, Laidlaw, Ken, Power, Mick J., and Shen, Jiliang. 2009. “Older People's Belief of Filial Piety in China: Expectation and Non-Expectation." Clinical Gerontologist 33.1: 21-38.

Wang, Tangjia. 2014. "Is Confucianism a Source of Corruption in Chinese Society? A New Round of Debate in Mainland China." Dao 13.1: 111-21.

Xie, Yu. 2013. "Gender and Family in Contemporary China." University of Michigan, Institute for Social Research 1-10.

Yeh, Kuang-Hui. 2003. "The Beneficial and Harmful Effects of Filial Piety: An Integrative Analysis." Pp. 67-82 in Progress in Asian Social Psychology: Conceptual and Empirical Contributions, edited by Kuo-Shu Yang, Kwang-Kuo Hwang, Paul B. Pederson, and Ikuo Daibo. Westport: Praeger.

Yeh, Kuang-Hui and Bedford, Olwen. 2003. "A Test of the Dual Filial Piety Model." Asian Journal of Social Psychology 6.3: 215-28.

Zhan, Heying Jenny and Montgomery, Rhonda J. V. 2003. "Gender and Elder Care in China: The Influence of Filial Piety and Structural Constraints." Gender \& Society: Official Publication of Sociologists for Women in Society 17.2: 209-29. 
Zimmer, Zachary and Kwong, Julia. 2003. "Family Size and Support of Older Adults in Urban and Rural China: Current Effects and Future Implications." Demography 40.1: 23-44. 